\title{
COMPREENSÃO CONSTITUCIONAL SOBRE O TRATAMENTO MÉDICO SEM TRANSFUSÃO DE SANGUE
}

\author{
ANDRÉ DEL NEGRI ${ }^{1}$
}

\begin{abstract}
RESUMO: Este ensaio sobre o tratamento médico sem transfusão de sangue, uma das discussões mais complexas no Direito brasileiro, quer ser um estudo jurídico com apoio na Constituição Federal e em normas de regência da conduta médica instituída por seus órgãos de classe, bem como atos normativos federais editados pela Administração Governativa e enunciados normativos infraconstitucionais, a fim de propor novos contornos teóricos.
\end{abstract}

PALAVRAS-CHAVE: Transfusão de Sangue; Direito à Vida; Auto-Determinação do Paciente; Colisão de Princípios; Direitos Fundamentais.

ABSTRACT: This assay on the medical treatment without blood transfusion, one of the most complex quarrels in Brazilian Law, aims at a legal study based on the Federal Constitution and on medical code of conduct norms issued by medical class organizations, as well as federal administrative norms edited by the Federal Administration and statutory norms, in order to propose new theoretical approaches. KEYWORDS: Blood Transfusion; Right to Life; Patient Self-Determination; Collision of Principles; Fundamental Rights.

SUMÁRIO: Introdução; 1. Objeto do estudo. Estratégias alternativas à transfusão de sangue. Quadro recaptulativo. Resumo temático; 2. Estado Constitucional e Democrático. Vida digna e sua dobradura na fala e na argumentação. Alinhamento do tema; 2.1. Sujeito e titularidade de direito. Vida discursiva. Destino ontológico da orientação na argumentação. Liberdade Constitucional e qualidade de vida. Algumas delimitações relevantes; 3. Mudança de paradigma jurídico e deslocamento interpretativo. Princípio da autonomia privada e pública. Um pequeno exercício de teoria da Constituição; 4 . Teorema da colisão de princípios. O mesmo e o outro. Sutura pela devida hermenêutica constitucional. A proporcionalidade é o domínio d'o-que-não-é-constitucional; 5. Situação ético-jurídica do médico e/ou instituição hospitalar. Errância do forçamento da absolutez; Conclusões; Referências Bibliográficas.

Artigo recebido em 18.08.2010. Pareceres emitidos em 30.11.2010, 15.12.2010 e 13.02.2011. Artigo aceito para publicação em 31.05.2011.

${ }_{1}^{1}$ Mestre em Direito Constitucional pela UFMG. Professor de Direito Constitucional e Teoria da Constituição na Faculdade de Direito do Triângulo Mineiro da Universidade de Uberaba (MG). Advogado-consultor. andredelnegri@uol.com.br 
SUMMARY: Introduction; 1. Object of study. Alternative strategies to blood transfusion. A recapitulating frame. Theme summary; 2. Constitutional and Democratic State. Dignified life and its unfolding in discourse and argumentation. Theme alignment; 2.1 - Subject and right entitlement. Discursive life. Ontological destination of argument's orientation. Constitutional freedom and quality of life. Some relevant specifications; 3. Legal paradigm shift and interpretative displacement. Principle of private and public autonomy. A small exercise of Constitutional Theory; 4. Theorem of principle collision. The same and the other. Suture in the name of proper constitutional interpretation. Proportionality is the domain of "thatwhich-is-not-constitutional"; 5. Physician's or medical facility's ethical-legal situation. Error in forcing the absolute; Conclusions; Bibliographical References.

\section{INTRODUÇÃO}

Após ser consultado a respeito de parecer jurídico sobre a compreensão constitucional no caso de recusa de tratamento médico sem transfusão de sangue por motivo religioso, mediante consentimento informado, consulta acompanhada de substancioso material médico-acadêmico relacionado ao tema, preparamos o presente estudo jurídico com apoio na Constituição Federal e em normas de regência da conduta médica instituída por seus órgãos de classe, bem como atos normativos federais editados pela Administração Governativa e enunciados normativos como o Código Civil e Penal.

Naturalmente, numa discussão como esta, defrontamo-nos com as seguintes perguntas:

1. Na hipótese de tratamento médico que envolva Testemunhas de Jeová é possível haver tratamento clínico sem sangue alogênico?

2. No caso de a resposta ao quesito anterior ser afirmativa, haveria à luz da Teoria Geral do Direito algum modo de se evitar, na ordem Constitucional vigente, a negativa de estratégias alternativas à transfusão? Pode o Judiciário negar cumprimento ao princípio da liberdade de consciência?

2. O direito à vida tem apenas um único aspecto, isto é, o de conservação biológica do corpo por intermédio da pulsão dos órgãos?

$\mathrm{O}$ tratamento médico sem transfusão de sangue e a questão religiosa são, portanto, os dois assuntos que ora nos propomos a enfrentar e esclarecer. Desta forma, defrontamo-nos com mais duas perguntas:

1. Qualquer paciente, idependentemente de religião, pode decidir sobre a execução de práticas diagnósticas ou terapêuticas?

2. Como entender a principiologia constitucional no tocante à liberdade de crença, e ao direito à privacidade e à dignidade humana?

Conforme razões de fato e de direito, que abaixo seguem, passemos à análise dos eixos de reflexão, ainda sob a seguinte observação: este artigo científico foi adaptado a partir de um parecer jurídico, o que implica frente a um limite de páginas algumas restrições na extensão do texto original, o qual foi adequado perante esta justificativa que se lê. Pretendendo, pois, este texto ser uma publicação de síntese, à evidência padece de alguns limites. 
Com efeito, note-se que pela dificuldade do assunto, e pelo apertado espaço, não descartamos a hipótese de voltar ao tema desta publicação num futuro ensaio, a fim de discutirmos as ferramentas de análise em intervenção médica ou cirúrgica, sem o consentimento do paciente, em casos de "iminente risco de vida", utilizando-se de suporte teórico adequado em Direito Penal, uma vez que neste artigo, o foco está direcionado para um estudo de hermenêutica constitucional e as tensões principiológicas que influenciam na superação do sistema de regras (normas infraconstitucionais).

\section{OBJETO DO ESTUDO. ESTRATÉGIAS ALTERNATIVAS À TRANSFUSÃO DE SANGUE. QUADRO RECAPTULATIVO. RESUMO TEMÁTICO}

Versa o presente parecer sobre um dos momentos altos do discurso de tratamento médico sem transfusão de sangue, uma questão difícil pelo desconhecimento de muitos e alguns confrontos de entendimento no campo profissional. Nesse cenário, a questão merece uma discussão à altura das dificuldades que representa. No fundo, o que existe hoje é uma dúvida se é possível contornar as exigências religiosas das Testemunhas de Jeová com o que há à disposição na medicina e no ordenamento jurídico-constitucional contemporâneos. Daremos, nessa primeira etapa de enfrentamento teórico, duas respostas.

Primeira: visto que as Testemunhas de Jeová acreditam que as transfusões de sangue não são recomendadas por trechos bíblicos (Gênesis 9:3, 4 / Levítico 17:13, 14 / Atos 15:19, 20), chega-se a uma determinação: as estratégias médicas alternativas à transfusão de sangue alogênico (de doador) é caminho imprescindível a ser percorrido.

Uma palavra a mais sobre a trilha aberta pela medicina. Tal como procuramos demonstrar, as Testemunhas de Jeová exigem que não se lhes deem, em nenhuma hipótese, transfusão de sangue total (ou glóbulos vermelhos, glóbulos brancos, plaquetas ou plasma). Com efeito, há, aí sim, o direito de as Testemunhas escolherem alternativas médicas às transfusões de sangue, o que, aliás, não exige muita tecnologia, nem novos medicamentos. ${ }^{2}$ Devidamente enaltecida por muitos médicos, as técnicas alternativas à transfusão são comemoradas no mundo todo. Considere-se o exemplo da

\footnotetext{
${ }^{2}$ Confira-se que há técnicas para evitar hemorragia e anemia sem transfusão de sangue. Eis alguns exemplos: a) Dispositivos cirúrgicos para minimizar a perda sanguínea (eletrocautério/eletrocirurgia, cirugia a laser, coagulador com raio de argônio, radiocirurgia esterotática, escalpelo ultra-sônio); b) Técnicas cirúrgicas e anestésicas para limitar a perda sanguínea (anestesia hipotensiva, hipotermia induzida, hemodiluição normovolênica, embolização arterial, equipe cirúrgica maior/tempo menor, posicionamento cirúrgico, divisão em etapas dos procedimentos complexos; d) Dispositivo e técnicas que limitam a perda sanguínea iatrogênica (oxímetro transcutâneo, oxímetro de pulso, equipamento de microcoletagem, fazer apenas exames essenciais); d) Exames de volume (cristalóides, lactato de ringer, solução salina normal, solução salina hipertônica); e) Agentes hemostáticos para hemorragia/coagulação (tópicos - avitene, gelfoam, oxycel, surgice injetáveis - ácido tranexâmico, desmoprestina, vitamina K). Conferir, ainda: Thure R L. As the blood suplly gets safer,experts still call for ways to reduce the need for transfusions. The Journal of the American Medical Association 1992; 268(6): 698-700.
} 
tolerância do paciente à anemia, que, como se sabe, é causada pela perda de hemoglobina do sangue, que reduz o transporte de oxigênio aos órgãos do corpo, o que, à evidência, debilita o paciente. O mais importante, neste caso, segundo os médicos, é a ocorrência de redução da taxa de hemoglobina. Se tal ocorrer de 10 para 08, evita-se o tratamento hemoterápico não consentido. Eis aí, em apertada síntese, a demonstração de uma técnica alternativa a custo reduzidíssimo. A efetividade desse meio poderia colocar a saúde em evidência e ainda elevar a economia nos hospitais. ${ }^{3}$

O mesmo se diga sobre a administração de eritropoetina (EPO) ao paciente. Recorde-se que esta substância (eritropoetina, também de baixíssimo custo) estimula o aumento dos valores de hemoglobina no sangue e deve ser usada no período pré-operatório. Dir-se-á o mesmo sobre o controle de hemorragia, o que pode ser evitado com o uso de eletrocautério ou com a utilização do tampão da cola de fibrina, que impede o sangramento após a dissecagem. $E$ volta ao tema a recuperação do sangue perdido (em até 50\%). Nestes casos, o aparelho aspira ao sangue do campo operatório e consegue processá-lo para posterior re-infusão no paciente. Prossiga-se com coagulação induzida com feixes do gás argônio. Taí, em fins didáticos, alguns exemplos de métodos alternativos no caso de hemoterapia não desejada pelo paciente e de excelentes resultados. Mas há outros meios terapêuticos. ${ }^{4}$

Dada, entretanto, sua disposição, como visto, a medicina sem sangue é, portanto, um novo campo que utiliza de estratégias seguras e eficazes de combinação de medicamentos, equipamentos e técnicas médico-cirúrgicas para reduzir ou evitar a perda sanguínea e para melhorar a perda de sangue do próprio paciente. Como visto, é uma ideia interessante, merecedora de mais estudos e pesquisas. Assim, como pode algumas pessoas olhar para a ciência e não perceber que isso é possível? Afora a obviedade, como todo

\footnotetext{
${ }^{3}$ Note-se que um dos problemas acarretados pelas transfusões de sangue ainda é o custo. Uma bolsa de sangue com 350 mililitros, por exemplo, até a data de publicação deste artigo, estava fixada em valores aproximados de $R \$ 300$ a $R \$ 800$. A maioria dos pacientes recebe de duas a três bolsas. Para tanto, verificar estudo publicado pela Editora do Ministério da Saúde, 2007. - Caderno de informação: sangue e hemoderivados: rede física, produção, gastos públicos com hemoterapia e consumo de hemoderivativos. p.: Il. Color. - (Série G. Estatística e Informação em Saúde). ISBN 978-85-334-1431-0. Parêntese: A coleção institucional do Ministério da Saúde pode ser acessada, na íntegra, na Biblioteca Virtual em Saúde do Ministério da Saúde: http://www.saude.gov.br/editora

${ }^{4}$ Sobre o assunto, há vários textos e abstracts de anesteologistas, hematologistas e outros especialistas com pesquisas ligadas ao tema. Para tanto, conferir: a) SPENCE, Richard K. Director of Sugical Education, Birmingham, Alabama, USA. e professor de cirurgia e chefe de departamento de cirurgia vascular em Camden, Nova Jersey, EUA. Artigo: The Status of Bloodles Surgery, in Transfusion Medicine Reviews, vol. V, $\mathrm{n}^{\circ} 4$ outubro de 1991,PP. 274-86 at 284. b) SOUZA, Zelita S. (professora de hematologia). Successfully Treating Jehovah's Witnesses Without Hemologous Blood, in Revista Paulista de Medicina, vol. 10 set/out, 1992, TM 17, Brasil. C) Vídeo fornecido pelo cliente: Transfusion alternatives: documentary series, 2004. Watch Tower Biblie and Tract Society of Pennsylvania. All rights reserved. Produced by Watchtower Biblie and Tract Society of New York, Inc. 25 Columbia Heights, Brooklyn, NY 11201-2483, U.S.A.
} 
mundo sabe, a ciência se baseia na revisitação (técnicas alternativas), não no lugar-comum (transfusão de sangue alogêncico).

Segunda: sim, temos um ordenamento jurídico-constitucional apto a conferir a possibilidade de exercício de crença e liberdade de consciência (art. $5^{\circ}$, incisos VI e VIII, CF/88), bem como a recusa de se submeter a determinados tratamentos médicos em detrimento da legalidade (art. $5^{\circ}$, inciso II) e do asseguramento da dignidade humana (art. $1^{\circ}$, inciso III), todos da Constituição Federal. Então, por que existe tanta dificuldade em aceitar essa hipótese levantada? De novo, tentaremos duas respostas.

Primeira: há dificuldade porque muitos desconhecem as técnicas de cirurgia sem sangue. Nunca se difundiu nos chamados meios de comunicação (TV, jornais, revistas e agora internet) técnicas de cirurgia sem sangue. Ao contrário, o que se vê, nas propagandas do governo federal, são apelos à doação de sangue. Tudo isso somado a uma sociedade que se alimenta de estigmas, o problema não poderia ser outro: a dificuldade de aceitação de novas técnicas. Acreditamos que a causa da não compreensão da leitura das Testemunhas de Jeová está mais ligada à formação ética das pessoas, um caso forte de conteúdo psíquico-moral; um conceito criado numa cultura vigente. ${ }^{5}$

Segunda: com esteio de que a vida é o direito mais importante dentro do ordenamento jurídico, o assunto se amarra a uma literatura jurídicoconstitucional que se coloca "bem resolvida" frente ao tema por utilizar de uma teoria da proporcionalidade (teoria hermenêutica que faz sopesagem de valores) que eleva o apreço à vida, sem saber a extensão do significante vida. $O$ problema se agrava porque muitos se apegam à teoria da proporcionalidade em um país onde a Constituição não tem o mecanismo de ajuste de direitos em ranking de importância (por essa teoria os princípios constitucionais podem ser maximizados ou minimizados). Advirta-se que não há princípios mais importantes que outros dentro do Texto Constitucional. Como em qualquer democracia, existe a solução hermenêutica via devido processo, instituição constitucionalizada que permite a reconstrução hermenêutica, caso a caso, a partir da discursividade ampla e isonômica daqueles que sofrerão os efeitos da decisão (partes processuais).

Feita a ressalva, percebe-se que a teoria hermenêutica da proporcionalidade (teoria desenvolvida na Alemanha) encontra dificuldades de resgate para 0 Direito Constitucional brasileiro nos dias atuais, pois não condiz com o paradigma jurídico adotado pelo art. $1^{\circ}$, da Escritura Constitucional. Cabe repetir que, hoje, o paradigma constitucional é o de Estado de Direito Democrático (projeto inacabado e em constante construção). Outro ângulo de discussão: em nenhum momento as Testemunhas de Jeová abdicam do "direito à vida" em atenção ao "direito de liberdade religiosa". Daí, não há que se falar em conflito de direitos fundamentais, porque a negativa de sangue alogênico não demonstra menosprezo à vida. Ao contrário, as Testemunhas de Jeová procuram

\footnotetext{
${ }^{5}$ LARAIA, Roque de Barros. Cultura: um conceito antropológico. Rio de Janeiro: Jorge Zahar, 2006.
} 
tratamento médico; dirigem-se a hospitais. Lutam contra a morte. Preservam vida biológica e prezam a vida argumentativa.

\section{ESTADO CONSTITUCIONAL E DEMOCRÁTICO. VIDA DIGNA E SUA DOBRADURA NA FALA E NA ARGUMENTAÇÃO. ALINHAMENTO DO TEMA}

No Estado Constitucional e Democrático (artigo $1^{\circ}$, caput, CF/88), é juridicamente assegurado ao titular de direito fundamental (cidadão parágrafo único, art. $1^{\circ}, \mathrm{CF} / 88$ ) construir compartilhadamente uma decisão judicial, por meio do devido processo (artigo $5^{\circ}$, inciso LV, CF/88), que autorize tratamento médico sem transfusão de sangue, quando for esta a sua opção. Por isso merece toda atenção a hermenêutica constitucional desenvolvida por magistrado de primeira instância, em resposta ao pedido de alvará judicial formulado pelo Ministério Público de Minas Gerais, o qual fundamenta que "a recusa de submeter-se à transfusão de sangue é providência legítima desde que haja manifestação consciente ou manifestação formal, como é o caso dos autos". 6

Tanto vale dizer, em sentido constitucional, que o processo (recinto teórico-discursivo) é que vai propiciar ao paciente o direito de participar, de forma ampla e isonômica, da construção de uma decisão judicial, autorizadora ou não da transfusão de sangue. Daí a importância de uma análise crítica acerca da titularidade do bem jurídico "vida digna", "liberdade" e "privacidade" como forma de execução de direito líquido e certo.

Tem-se afirmado que na contemporaneidade democrática, a vida não pode mais ser interpretada em uma acepção puramente jurídico-biológica (fecundação do óvulo-nidação-nascimento-morte). Vemos, portanto, muito mais que isso. ${ }^{7}$ Não se trata de uma leitura de determinado segmento religioso, mas de uma linha de pensamento jurídico-filosófico-processual-constitucional inerente a qualquer convicção (agnósticos, judeus, cristãos, islamitas, hindus, budistas, ateus, taoístas...).

Neste sentido, os representantes legais do paciente que se encontra inconsciente ou não, podem participar da construção de uma decisão, autorizadora ou não do tratamento médico sem sangue. Eis a relevância de demarcação das chamadas "formas de manifestação da vontade." ${ }^{8}$ Assim, o fato de não existir nenhuma forma prescrita em lei para a prática de um determinado ato, ao paciente está assegurado a liberdade de forma (art. 107, $\mathrm{CC}$ ), uma vez que para a validade da declaração da vontade não há que se falar em um "modelo especial," senão quando a lei expressamente a exigir.

\footnotetext{
${ }^{6}$ Ato decisional da $4^{\text {a }}$ Vara Cível da Comarca de Uberlândia, MG, - Magistrado: Walner Barbosa Milward de Azevedo, J. 6.2.2009.

${ }^{7}$ DEL NEGRI, André. Teoria da Constituição e do Direito Constitucional. Belo Horizonte: Editora Fórum, 2009, p. 334.

8 PEREIRA, André Gonçalo Dias. O consentimento informado na relação médico-paciente estudo de direito civil. Coimbra: Coimbra Editora, 2004.
} 
Vemos, portanto, que a nomeação de "procurador de cuidados de saúde" ou até os denominados "testamentos vitais" são meios de manifestação da vontade que possuem legitimidade jurídica.

Isto se explica pelo fato de que todos, na democracia, sem exceção, têm o direito à vida discursiva não podendo ser limitado no exercício do contraditório e da ampla defesa. Dessa forma, não se justifica, realmente, que o conteúdo do significante vida digna, seja ditado pelo aparelho estatal, mas sim por quem é titular do direito (cidadão/paciente/intérprete do texto constitucional).

2.1. Sujeito e titularidade de direito. Vida discursiva. Destino ontológico da orientação na argumentação. Liberdade Constitucional e qualidade de vida. Algumas delimitações relevantes.

A prática de cirurgia sem sangue envolve casos e circunstâncias de extrema complexidade e alta relevância, já o dissemos. Posto, a sua vez, o caráter complexo do tema, nossa tentativa de mostrar o desvio de perspectiva em que vem sendo encarado o assunto, decorrente do sentido interpretativo estrito e não lato em que deveria se raciocinar o tema, faz do paradigma do Estado de Direito Democrático, um esteio seguro para reflexão. Nele se instalou a filosofia do direito, remontando a uma hermenêutica constitucional que permitiu reconhecer os cidadãos como coautores do ordenamento jurídico. ${ }^{9}$ Só de um ângulo para ilustração, a única fonte de soberania é o povo, conforme excelente pesquisa de Jorge Carpizo. ${ }^{10}$ Diante desse quadro (soberania no núcleo da cidadania), a titularidade de direito só pode mesmo ser do cidadão (parágrafo único, art. $1^{\circ}, \mathrm{CF} / 88$ ).

Queira-se, por amor à tradição, enxergar o direito à vida como algo absoluto (certo e definitivo). Já vai longe o tempo em que essa novidade antiquíssima modificou-se, uma vez que as teorias são falíveis e "sujeitas a desmentidos futuros". ${ }^{11}$ Por isso, merecem apenas "endosso provisório." Isso se explica pelo fato de que no atual paradigma teórico-constitucional o paciente, sendo o legítimo titular do bem jurídico "vida digna", tem o direito de reivindicar a prática de cirurgia sem sangue e de buscar novos conceitos eliminadores de preconceitos.

Uma palavra a mais sobre o assunto: a bem dizer, a compreensão da vida, na Ciência do Direito (estudo de um Direito não-estático), passa pela compreensão da linguagem, da argumentação e da reivindicação de direitos. É a implementação desses princípios que garantirão o direito à vida digna das pessoas (dignidade humana - art. $1^{\circ}$, inciso III, CF/88).

\footnotetext{
${ }^{9}$ HABERMAS, Jürgen. Direito e democracia: entre facticidade e validade. v. 2. Rio de Janeiro: Tempo Brasileiro, 1997.

${ }^{10}$ CARPIZO, Jorge. El poder: su naturaleza, su tipologia y los medios de comunicación masiva. Boletín Mexicano de Derecho Comparado (Nueva Serie), México, v. 32, n. 95, p. 321-356, mayo-ago. 1999, p. 321-356.

${ }^{11}$ OLIVA, Alberto. Filosofia da Ciência. Rio de Janeiro: Jorge Zahar Editor, 2003, p. 11.
} 
Sabe-se que as Testemunhas de Jeová acreditam que as transfusões de sangue não são recomendadas por trechos bíblicos (uma questão de crença, de fé - algo inerente à esfera privada do indivíduo), o que causa à sociedade algumas resistências, pois, para muitos, essa prática pode, à primeira vista, parecer ilegal. Aliás, é fácil intuir muitas vozes, em uníssono, atribuindo interpretação equivocada para o caso da não-transfusão de sangue. No entanto, se há o consentimento do paciente, seja por vontade expressa ou presumida por meio de documento legal (carta de diretrizes - documento utilizado pelas Testemunhas de Jeová), quando acometido por doença em que se cogita cirurgia e a prática da doação de sangue seja decisão do profissional de saúde que lhe assiste, a recusa é convivente com a própria ideia de Estado Laico e do direito de ser respeitado em sua liberdade de consciência e crença religiosa (art. $5^{\circ}$, incisos VI e VIII, CF/88). Destaque-se, desde logo, que no caso das Testemunhas de Jeová não há a provocação da morte do paciente enfermo (não se abre mão de vida biológica). O que se coloca é apenas a utilização de outros métodos terapêuticos, que não a transfusão de doador. Se aceita quaisquer outros fluídos.

3. MUDANÇA DE PARADIGMA JURÍDICO E DESLOCAMENTO INTERPRETATIVO. PRINCÍPIO DA AUTONOMIA PRIVADA E PÚBLICA. UM PEQUENO EXERCÍCIO DE TEORIA DA CONSTITUIÇÃO

Se é verdade que todo esse itinerário demonstra a dificuldade de compreender a cirurgia sem sangue, deve-se ainda acrescer a nebulosidade de saber que a Constituição Federal de 1988 (paradigma jurídico-constitucional) promoveu um deslocamento interpretativo na esfera privada e pública. Para Jürgen Habermas, um paradigma jurídico traceja um modelo de sociedade contemporânea para explicar como direitos constitucionais e princípios devem ser lidos e implementados num dado contexto, bem como as funções a eles normativamente atribuídas. ${ }^{12}$

Menelick de Carvalho Netto $^{13}$ dedicou importantes páginas à distinção entre pré-modernidade e modernidade. Sem discutir em profundidade, limitemo-nos, de passagem, a assinalar, com apoio no citado autor, que dentro desse período chamado pré-moderno o Direito não se distinguia da Moral, nem dos Costumes. Ao cuidar da distinção entre Direito e Moral, Maria Fernanda Salcedo Repolês ${ }^{14}$ afirma que a Moral opera num "jogo interno de argumentação, não tendo por isso que institucionalizar as decisões que são tomadas. Ela pretende a aceitabilidade universal das normas (...)". Ainda no dizer de Repolês, a Moral sequer tem "um sistema hierárquico de normas,

\footnotetext{
12 HABERMAS, Jürgen. Direito e democracia: entre facticidade e validade. Rio de Janeiro: Tempo Brasileiro, 1997.

${ }^{13}$ CARVALHO NETTO, Menelick de. Requisitos pragmáticos da interpretação jurídica sob o paradigma do Estado Democrático de Direito. Revista de Direito Comparado. Belo Horizonte, v. 3, p. 482-486, maio 1999, p. 482-486.

REPOLÊS, Maria Fernanda Salcedo. Habermas e a Desobediência Civil. Belo Horizonte: Mandamentos, 2003, p. 104.
} 
que orientam os sujeitos para a ação. Por isso a moral pós-convencional é deficiente cognitivamente, porque ela não gera obrigações institucionais, não gera normatividade (...). Já o Direito mantém um nível de saber altamente acional e artificial, por meio da formação de uma dogmática jurídica e de uma Ciência do Direito, que Ihe permitem estruturar-se cognitivamente."15

Se refletirmos o tema "vida", "aborto", "transfusão de sangue" (entre outras tantas questões), vai-se perceber que todos esses conteúdos eram tratados como assuntos divinos, como assuntos moralizantes. Não havia a ideia de direitos fundamentais do indivíduo (pessoa/cidadão). Isso era inexistente. Havia, sim, a leitura de que o homem era coisa (objeto) à disposição de outros homens ou à disposição da divindade. Importa acentuar que face ao Direito moderno (separação da moral, da ética, da política) o acordo normativo denominado "Direito" está constantemente procurando mostrar a necessidade de ser legítimo. ${ }^{16}$

O Estado de Direito Liberal, que, como origem, historicamente se remete à liberdade econômica, influência que se fez sentir na fomentação da livre concorrência, que fez acelerar o abuso sobre os menos favorecidos e o surgimento do Estado como instrumento de opressão política e econômica, demonstrou a ideia geral de o homem ser o senhor absoluto do seu corpo. O Estado se abstinha (ao máximo) de intrometer nas relações sociais dos indivíduos.

Apercebendo-se, entretanto, da necessidade de reformulação desse período, os Estados começaram a modificar as suas Constituições. Incentivados pela Encíclica Rerum Novarum (1891), do Papa Leão XIII, a qual proclamou atenção ao lado social, refutando a idéia de capitalismo selvagem, efetivou-se uma das maiores transformações nesse período. Daí, necessário sintetizar que, sob a égide socializante, o Estado mostrou-se mais intervencionista, mais atuante e preocupado em estimular o crescimento e o desenvolvimento das inúmeras atividades ligadas às áreas da saúde, educação, cultura, família e previdência social. Por esse motivo, surge, pois, o Estado de Direito Social. Socializante e paternalista prolongou-se pela literatura jurídica.

Destaque-se que isso levou "ao entendimento de que ao juiz, representando um Estado preocupado com o bem-estar coletivo, caberia impor seu conhecimento e senso de justiça para corrigir as agruras dos desequilíbrios sociais, ainda que tal implicasse inobservância dos textos legais" (referência a André Leal). ${ }^{17} \mathrm{E}$ já se ajunta o surgimento das ditaduras, em que o fortalecimento dos poderes dos juízes se adiantava em colocar nas

\footnotetext{
15 REPOLÊS, Maria Fernanda Salcedo. Habermas e a Desobediência Civil. Belo Horizonte: Mandamentos, 2003, p. 108.

${ }^{16}$ CARVALHO NETTO, Menelick de. A hermenêutica constitucional sob o paradigma do Estado Democrático de Direito. In. CATTONI, Marcelo (Coord.). Jurisdição e hermenêutica constitucional. Belo Horizonte: Mandamentos, 2004.

${ }^{17}$ LEAL, André Cordeiro. O contraditório e a fundamentação das decisões no direito processual democrático. Belo Horizonte, Mandamentos, 2002, p. 28.
} 
mãos do magistrado a ideia de processo como instrumento da jurisdição (jurisdição do juiz, não das partes). Não se dá entre nós que os problemas amenizaram. O que se dá, ao reverso, é que o processo centrado na pessoa física do juiz trouxe contradição institucional gravíssima. Confiado ao magistrado, o processo no Estado Social adquire perigosa carga ideológica (paz social, bem comum, fins sociais, bom senso, justiça pública...). A partir daí, as lacunas da lei passam a ser colmatadas pelo juiz que cria o direito, o que coloca as partes processuais na condição de meros espectadores e o decididor a elevar-se a um grau de superioridade decisional.

Detenhamo-nos que a Constituição de 1934 permitiu essa experiência constitucional. É cediço que a noção de um direito paternalista posto à sociedade como condição de manter o equilíbrio foi um devaneio. Esse "maternizar" os cidadãos (como preocupação central do Estado) ainda é encontrado em muitas decisões judiciais e em várias passagens da ordem jurídica vigente, como no caso do Código Civil de 2002 (art. 1.641, inc. III), o qual diz que é obrigatório o regime da separação de bens no casamento para pessoas maiores de 60 (sessenta) anos. Diga-se o mesmo do artigo 1.566, inciso I, ao falar em fidelidade como o primeiro dos deveres conjugais. É óbvio o descompasso desses artigos ante a Constituição e seu projeto de sociedade descentrada. Esquece-se que o Estado não tem que invadir a esfera privada de ninguém ao ponto de escolher a forma de se comportar em um relacionamento pessoal (íntimo). A escolha, nesse caso, deve ser feita entre os próprios casais, que discursivamente acertarão a relação, a fim de decidir, dali em diante, o que serão. A autonomia da vontade é neutralizada nestes casos. A lição é atualíssima e o que se percebe é o Estado infantilizando seus cidadãos, ao ponto de uma pessoa não poder manifestar sua vontade (regime de bens, por exemplo), por causa da idade cronológica (sessenta anos).

Não necessariamente alheio aos excessos do debate, o constituinte brasileiro demarcou um dos mais importantes momentos do constitucionalismo brasileiro e mundial exatamente após a criação do Estado de Direito Democrático (art. $1^{\circ}, \mathrm{CF} / 88$ ). Surgiu, em consequência, um marco teórico acerca de como os princípios constitucionais devem ser lidos, bem como 0 papel do cidadão (visto como coautor do discurso normativo).

É das perplexidades sobre o paternalismo radicalizado na ditadura que o raciocínio dos constituintes promoveu a necessidade desenfreada da busca de elementos constitucionais para promover um verdadeiro deslocamento no país, uma vez que as sociedades atuais estão cada vez mais multiculturais, multiéticas. Foi assim que o Brasil, a partir de 1988, trouxe uma proposta interessante de modelo de Estado Constitucional, pois além de reconhecer as propostas que tiveram surgimento no antigo Welfere State do século XX (condições mínimas de educação, saúde, segurança, moradia) como direitos básicos para a vida dos cidadãos, a Escritura Constitucional vigente estendeu o conceito de cidadania à esfera social, o que nos levou a uma releitura significativa dos atributos de sociedade civil, povo, comunidade jurídica, 
cidadão, administração-governativa, esfera público/privada, Estado, jurisdição, decisão, interesse público, direitos fundamentais, desobediência civil, excluído social, segurança jurídica, Direito Econômico, maiorias/minorias, direito à vida digna, transfusão de sangue e liberdade de consciência. Seja como for, tais concepções ganharam especial proeminência pós-88 e suplicam revitalização, buscando argumentações e interpretações que melhor se ajustam ao eixo teórico da Democracia.

A construção desse novo paradigma jurídico, entretanto, baseado nos princípios da dignidade, privacidade, no respeito à liberdade de crença, vai depender dos esforços comum da sociedade, particularmente do Judiciário, em entender a superação dos outros paradigmas, porque no Estado Constitucional e Democrático, a Constituição deve ser vista como um texto aberto, passível de reconstrução e de fiscalização por todos os cidadãos.

$\mathrm{Na}$ contemporaneidade os indivíduos são dotados de dignidade, respeito e consideração. Com isso, o que se quer dizer é que a cirurgia sem sangue é um ato de vontade do paciente, independente de religião. Com ela, o princípio da dignidade humana é exercitado e o enfermo sai da condição de objeto (coisa - aquilo que está fora do Ser - Heidegger) ${ }^{18}$ e ocupa a condição de pessoa, algo que condiz com as diretrizes de um Estado de Direito Democrático (matiz fundamental de uma série de reflexões). Nessa situação não há como obrigar o paciente a um determinado comportamento. As pessoas são vivas e livres, mas viver não pode ser sinônimo de um simples respirar biológico. ${ }^{19}$ Ademais, na constitucionalidade brasileira, os princípios constitucionais da dignidade humana, da autonomia da vontade e da liberdade de autodeterminação do ser humano têm força normativa plena, imediata (art. $5^{\circ}, \S 1^{\circ}, \mathrm{CF} / 88$ ). Foi assim que o estilo enfático de Habermas sempre foi divulgado em alto sentido: princípios da autonomia privada e pública são chaves para uma boa compreensão democrática. O tema é altamente relevante. Se cidadãos são autores do direito, somente podem exercer sua autonomia pública, na medida em que sua autonomia privada for assegurada. ${ }^{20}$

4. TEOREMA DA COLISÃO DE PRINCÍPIOS. O MESMO E O OUTRO. SUTURA PELA DEVIDA HERMENÊUTICA CONSTITUCIONAL. A PROPORCIONALIDADE É O DOMÍNIO D'O-QUE-NÃO-É-CONSTITUCIONAL

No Estado de Direito Democrático (art. $1^{\circ}, \mathrm{CF} / 88$ ) não há nenhuma lei que obrigue alguém a se submeter à transfusão de sangue, nem existe razão para o Judiciário se comportar como um superego de uma sociedade órfã ${ }^{21}$ avocando decisões eminentemente médicas no determinar ser necessária

\footnotetext{
${ }^{18}$ HEIDEGGER, Martin. Que é uma coisa? Lisboa: Edições 70, 1992.

19 DEL NEGRI, André. Teoria da Constituição e do Direito Constitucional. Belo Horizonte: Editora Fórum, 2009, p. 337.

${ }^{20}$ HABERMAS, Jürgen. Direito e democracia: entre facticidade e validade. Rio de Janeiro: Tempo Brasileiro, 1997, v. II, p. 146.

${ }^{21}$ MAUS, Ingeborg. Judiciário como superego da sociedade: o papel da atividade jurisprudencial na sociedade órfã. Revista Novos Estudos, São Paulo, v. 58, p. 183-202, nov. 2000.
} 
ou não a realização de uma transfusão de sangue ou qualquer outra terapia. A competência do Judiciário, pós-88, é tão somente voltada a apreciação de pedidos de lesão ou ameaça de lesão a direito (CF/88- art. $5^{\circ}, \mathrm{XXXV}$ ), não o da prestação médica, impondo ou decidindo qual o tratamento médico mais indicado a um determinado paciente. Para tudo resumir, "no Direito Democrático, o texto normativo não necessita de um guardião."22

O serviço judiciário é um setor de funcionamento do Estado e que tem o comprometimento de prestar serviço público adequado e eficiente. Nessa quadra jurídica o Tribunal de Justiça do Estado de Mato Grosso a isto chegou:

Não cabe à administração pública avaliar e julgar valores religiosos, mas respeitá-los. A inclinação de religiosidade é direito de cada um, que deve ser precatado (...). O que se põe em relevo é o direito à saúde e a obrigação de o Estado proporcionar ao cidadão tratamento médico que não implique em esgarçamento à sua liberdade de crença religiosa. ${ }^{23}$

Destaque-se que o comportamento do Judiciário na forma de um Pai (Estado-provedor), pode criar formas embriagadas de expressões visionárias. Nesse ínterim, na procura pela solução "mais justa ao caso concreto", os juízes (cavaleiros da moralidade), conhecedores dos valores e comportamentos corretos de uma sociedade órfã (de novo a referência a Ingeborg Maus), ${ }^{24}$ adotam um discurso de predestinação (domínio retórico do Pai) e a decisão acaba girando em torno de argumentos metajurídicos. Uma simples recordação: não cabe ao magistrado impor seu conhecimento e "senso de justiça" nas decisões judiciais. Decisão não é axiologia (livre convencimento - convicção - do julgador), mas sim deontologia com apoio na teoria da lei democrática.

Em consequência é que aparece a denominada "jurisprudência de valores", que é um comportamento interpretativo bastante utilizado pelas Cortes Constitucionais na Europa (a denominada teoria da proporcionaldiade). Assim, no dizer de Álvaro Ricardo de Sousa $\mathrm{Cruz}^{25}$ as Cortes Constitucionais, a pretexto de considerarem a dignidade humana um metavalor, não aceitam nenhuma ponderação a fim de violá-lo. Daí a indagação do referido autor: "a dignidade da pessoa humana, tomada apenas como um valor, mesmo que entendido como supremo, seria critério suficiente de racionalidade para a tomada de decisões jurídicas ${ }^{26}$ À obviedade que a resposta é não.

${ }^{22}$ MADEIRA, Dhenis Cruz. Processo de conhecimento e cognição: uma inserção no Estado Democrático de Direito. Curitiba: Juruá, 2008, p. 29. Note-se que o referido autor re-pensou o Processo de conhecimento, a Cognição e o instituo da prova, propondo novos contornos teóricos compatíveis com o Direito na democracia.

${ }^{23}$ TJMT, 5a Câm. Civ., Ag 22395/206, Rel. Des. Sebastião de Arruda Almeida, J. 31.05.2006.

${ }^{24}$ MAUS, Igeborg. Judiciário como superego da sociedade: o papel da atividade jurisprudencial na sociedade órfã. Revista Novos Estudos.

${ }^{25}$ CRUZ, Álvaro Ricardo de Souza. Habermas e o Direito Brasileiro. Rio de Janeiro: Lumen Juris, 2006, p. 139-140.

${ }^{26}$ CRUZ, Álvaro Ricardo de Souza. Habermas e o Direito Brasileiro. Rio de Janeiro: Lumen Juris, 2006, p. 140. 
Foi exatamente essa questão que levou Jürgen Habermas ${ }^{27}$ a dizer que "tal jurisprudência de valores levanta realmente o problema da legitimidade (...), pois ela implica um tipo de concretização de normas que coloca a jurisprudência constitucional no estado de uma legislação concorrente".

José Emílio Medauar Ommati, ${ }^{28}$ em estudo preciso, deixou grande contribuição para os estudiosos de Hermenêutica Constitucional ao tecer críticas ao princípio da proporcionalidade e a Constituição como "ordem concreta de valores." Depreende-se, da referida pesquisa, que o princípio da proporcionalidade nasceu e se desenvolveu na doutrina e jurisprudência alemãs (as quais têm recebido duras críticas de sérios juristas), tendo sido "transportado para o Brasil como forma de resolver conflitos jurídicos", e, como tal, no Brasil, a proporcionalidade surge a partir da ideia de razoabilidade da doutrina norte-americana (Cf. o leading case Lochener v. New York, em 1905). Parêntese: convém pontuar que o citado autor não vê diferença qualitativa entre razoabilidade e proporcionalidade e é terminativamente contrário a decisões fundamentadas nesses critérios.

$\mathrm{Na}$ análise feita por Medauar Ommati ${ }^{29}$ pode-se falar que é somente a partir da década de 70 que o Supremo Tribunal Federal, paulatinamente, passa a substituir o termo razoabilidade (da doutrina norte-americana) por proporcionalidade. E tem mais: a partir daí, o critério da proporcionalidade passa a ser um método utilizado pelo STF para resolver colisão de princípios jurídicos. De lá para cá, tornou-se uma "fórmula mágica", um método capaz de "garantir a verdade", o que, para o ilustrado professor, "transforma o Direito e a Constituição em uma ordem concreta de valores, transformando os princípios em comandos axiológicos passíveis de otimização, e, assim, de aplicação na medida do possível. Com isso, as normas jurídicas perdem seu caráter deontológico fragilizando o próprio código binário do Direito., 30 De acordo com referido autor, é assim que o "princípio da proporcionalidade possibilita verdadeiro decisionismo judicial."

Não é outra a constatação feita por Friedrich Müller ${ }^{31}$ e por Virgílio Afonso da Silva. ${ }^{32} \mathrm{O}$ primeiro, diz que o procedimento da ponderação (balanceamento

\footnotetext{
27 HABERMAS, Jürgen. Direito e democracia: entre facticidade e validade. Rio de Janeiro: Tempo Brasileiro, 1997, v. 1, p. 320.

${ }^{28}$ OMMATI, José Emílio Medauar. O princípio da proporcionalidade e a Constituição como ordem concreta de valores. Revista de Direito Constitucional e Internacional. São Paulo: Revista dos Tribunais. Ano 15. janeiro-março 2007, p. 109- 128.

${ }^{29}$ OMMATI, José Emílio Medauar. O princípio da proporcionalidade e a Constituição como ordem concreta de valores. Revista de Direito Constitucional e Internacional. São Paulo: Revista dos Tribunais. Ano 15. janeiro-março 2007, p. 113.

30 OMMATI, José Emílio Medauar. O princípio da proporcionalidade e a Constituição como ordem concreta de valores. Revista de Direito Constitucional e Internacional. São Paulo: Revista dos Tribunais. Ano 15. janeiro-março 2007, p. 110.

${ }^{31}$ MÜLLER, Friedrich. Métodos de Trabalho do Direito Constitucional. São Paulo: Max Limonad, 2000, p. 35-36.

${ }^{32}$ SILVA, Virgílio Afonso da. A constitucionalização do direito: os direitos fundamentais nas relações entre particulares. São Paulo: Malheiros, 2005.
} 
de bens e interesses) traz perigo ao dar prioridade a uma norma em detrimento de outra. Já o segundo, praticamente no mesmo sentido crítico, diz que a proporcionalidade não é cabível porque a ponderação já foi feita pelo constituinte e pelo legislador ordinário.

Por tudo isso, vem a lume a necessidade de desmistificação de um Judiciário moralista, pois, no Direito Democrático, além de as "verdades serem provisórias" (ciência), a interpretação do Direito não se faz pela aclamação de proporcionalidades (comandos axiológicos). Do contrário, se os princípios fossem entendidos como valores, bens, interesses (códigos graduais de valor) seria, numa metáfora grosseira, como ir a um supermercado político e escolher, na gôndola jurídica, dentre os princípios constitucionais disponíveis, aquele que melhor the convém num dado momento (regra da preferência). Seria de conseguinte, o mesmo que relembrar a figura de Procusto, no mito de Perseu, ${ }^{33}$ como aquela figura de má índole que, dono de um leito de ferro criado para com a finalidade de amarrar todos os viajantes que lhe caíam às mãos, cortava-Ihes as pernas se elas fossem maiores que o leito, e Ihes espichava quando menores. É essa elasticidade axiológica de princípios jurídicos que acaba transformando a hermenêutica constitucional num pêndulo que oscila em terreno movediço, e sem uma análise detida das peculiaridades de cada caso concreto (elemento, meio e instrumento de prova no Processo). ${ }^{34}$ Tem-se de ver que esse "princípio" ou "método" da proporcionalidade não encontra esteio normativo na Constituição Brasileira de 1988.

É dessa forma que, em Robert Alexy, ${ }^{35}$ o porta-voz do julgar as decisões do legislador, parece inatingível conceber uma teoria da proporcionalidade (regra da adequação, regra da necessidade e regra da ponderação), com uma racionalidade que se encaminha por critério da preferibilidade do decididor.

É lugar-comum dizer que no caso das Testemunhas de Jeová há colisão entre vida e liberdade religiosa. Tão equivocado, tão distante. A liberdade, em seu completo sentido, é inconcebível se não houver vida, em especial vida argumentativa. Quando se opta por outro método terapêutico, que não o sangue alogênico, o que se dá é a procura por um método que preserve vida biológica.

O que parece sempre difícil demonstrar aos saudosistas de um constitucionalismo não-democrático de Direito (e, que, infelizmente ainda vêm ensinando, salvo raríssimas exceções, uma hermenêutica predestinada ao sábio-julgador) é que a teoria da proporcionalidade está fora de esquadro no marco teórico do processo constitucional democrático. Não se pode conceber mais na contemporaneidade, uma hermenêutica desenvolvida em métodos clássicos de interpretação do positivismo (absolutização do método)

${ }^{33}$ BULFINH, Thomas. O Livro de Ouro da Mitologia. Rio de Janeiro: Ediouro, 2002, p. 187.

34 LEAL, Rosemiro Pereira. Teoria geral do processo: primeiros estudos. Rio de Janeiro: Forense, 2010, p. 204 et seq.

${ }^{35}$ ALEXY, Robert. Derecho y razón práctica. México: Distribuciones Fontamara, 1993, p. 32. 
ou por uma abordagem proporcionalista (códigos graduais de valor) que transforma os princípios em comandos axiológicos, passíveis de otimização (decisionismo judicial).

Os conteúdos normativos (igualdade, dignidade humana, vida, liberdade...) têm que ser examinados pelo eixo hermenêutico do Devido Processo Constitucional (núcleo discursivo nas democracias) aberto a todos os integrantes de uma sociedade descentralizada. Eis por que uma hermenêutica jurídica contemporânea tem que atender aos princípios institutivos do Processo (devida hermenêutica constitucional), na preparação de um provimento final (decisão). Assim, para manejar princípios (normas deontológicas), há de se fixar atenção à teoria da prova - elemento, meio e instrumento de prova ${ }^{36}$ como marcos formais do Processo Constitucional (campos hermenêuticos de dicção procedimental onde os argumentos são levados pelas partes processuais a fim de sofrer uma cognição por todos aqueles que sofrerão os efeitos do provimento final). São estas, no nosso entender, as formas neutralizantes da vontade axiológica (livre conviç̧ão) do juiz-intérprete-aplicador.

\section{SITUAÇÃO ÉTICO-JURÍDICA DO MÉDICO E/OU INSTITUIÇÃO HOSPITALAR. ERRÂNCIA DO FORÇAMENTO DA ABSOLUTEZ.}

Está exposto no art. $5^{\circ}$, inciso VI, do Texto Constitucional Brasileiro, que "é inviolável a liberdade de consciência e de crença (...)," e, no inciso VIII, que "ninguém será privado de direito por motivo de crença religiosa (...)".

Por isso, ao explicar os direitos do paciente, o Código de Ética Médica brasileiro, resolução promulgada em maio de 2010, em meio a suas normatizações, que vieram aclarar as recomendações constitucionais, acaba com a figura do médico autoritário e prescreve uma série de regras que buscam a implementação de direitos fundamentais já assegurados na Escritura Constitucional. À evidência interpretativa, o Código não proíbe ao paciente o direito de escolher alternativas médicas às transfusões de sangue e o que se vê é a necessidade de o médico mencionar os riscos envolvidos na terapia transfusional ou se há tratamentos mais seguros. É o que se verifica no Capítulo IV (Direitos Humanos - art. 22) que é defeso ao médico "deixar de obter consentimento do paciente ou de seu representante legal após esclarecê-lo sobre o procedimento a ser realizado (...)", bem como "desrespeitar o direito do paciente ou de seu representante legal de decidir livremente sobre a execução de práticas diagnósticas ou terapêuticas..." (Capítulo V - art. 31 - relação com pacientes e familiares).

Uma condição a mais: as alternativas médicas às transfusões de sangue, ao utilizar de estratégias e técnicas médico-cirúrgicas para reduzir ou evitar a perda sanguínea e para melhorar a perda de sangue do próprio paciente, não exime o médico de conhecê-las. É o que está expresso no Capítulo I (princípios fundamentais-V): "Compete ao médico aprimorar continuamente

${ }^{36}$ LEAL, Rosemiro Pereira. Teoria geral do processo: primeiros estudos, p. 204 et seq. 
seus conhecimentos e usar o melhor do progresso científico em benefício do paciente." Outro ponto a ser lembrado: é vedado ao médico "deixar de usar todos os meios disponíveis de diagnóstico e tratamento, cientificamente reconhecidos e a seu alcance, em favor do paciente (art. 32)."

Destaque-se, entretanto, outro fator que torna o tratamento médico sem sangue mais nítido. O conceito de saúde para a Organização Mundial da Saúde (OMS), fundada em 7 de abril de 1948 (desde então o Dia Mundial da Saúde), não representa apenas ausência de doença, mas também bem-estar físico, mental e social do indivíduo e a não-violação a valores ético-culturais.

Pois bem. A este propósito, adicione-se outro: o ponto comum que orienta essas reflexões é o de que ninguém será privado da liberdade ou de seus bens sem o devido processo (art. $5^{\circ}$, LIV). Flagra-se que a liberdade humana não se exaure na livre locomoção ou na liberdade de expressão (os animais também possuem ambas, ainda que a última seja corporal ou por grunhidos), e muito menos no livre arbítrio. O grande passo é ver a liberdade como função argumentativa exercitada no mundo de teorias pensadas. ${ }^{37}$ Esse é um ponto determinante. Essa linguagem humana descritivoproblematizante é que leva à invenção da crítica, à eliminação de erros, e, por consequência, à mudança de pensamentos num país, numa profissão.

Ainda uma vez repetiremos: há necessidade de se descobrir em que sociedade vivemos, qual o modelo de paradigma jurídico-constitucional foi adotado pelo país, o que é direito fundamental do indivíduo, eis a relevância. E confirmamos. Se as sociedades multiéticas é o eixo central na altamodernidade, a necessidade de se operacionalizar um multiculturalismo é questão de garantia fundamental. Aliás, a partir de Habermas, compreendemos que o Direito hoje deve ser visto como um projeto inacabado, operacionalizador de sociedades descentradas (pós-metafísicas), onde não há mais homogeneidade sobre conceitos de moral, ética, religião... ${ }^{38}$. A liberdade de consciência, portanto, é assunto a ser refletido por todos os profissionais de saúde. Dúvida não se desfaz com a repetição do lugar-comum. Atos judiciais não serão legítimos sem o compartilhamento decisório. Em vez de condenações morais, reflexões jurídico-filosóficas. Em vez de estigma, compreensão multicultural. Em vez de estreitamentos, estudo e pesquisa. Quem vive tutelado, não é livre, decerto.

\section{PRINCIPAIS CONCLUSÕES}

Diante dos fatos expostos na consulta e na análise teórica do problema proposto, ficou explícita a hipótese teórica de haver condições jurídicas para as seguintes situações:

a) Claro na possibilidade de haver condições terapêuticas alternativas à transfusão de sangue alogênico (procedimentos médicos alternativos, aparelhos

\footnotetext{
${ }^{37}$ POPPER, Karl; ECCLES C. John. O Eu e seu Cérebro. Campinas: Papirus, 1995.

${ }^{38}$ HABERMAS, Jürgen. Direito e democracia: entre facticidade e validade. Rio de Janeiro: Tempo Brasileiro, 1997.
} 
e técnicas cirúrgicas e anestésicas, bem como agentes hemostáticos e terapêuticos que não contenham hemoderivados), pode-se concluir que a objeção da Testemunha de Jeová encontra esteio na constitucionalidade brasileira, porque ao optar livremente pela não transfusão de sangue, não quer dizer que se está rejeitando todos os tratamentos médicos e nem solicitando o direito de morrer. O paciente "Testemunha de Jeová" ao escolher um determinado tratamento médico, está defendendo seus valores, sua crença religiosa, sua liberdade de consciência, sua dignidade humana e privacidade como cidadão e intérprete da Constituição Federal.

b) A questão refoge à famosa discussão do conflito entre o direito à vida e direito à liberdade religiosa, com prevalência do primeiro (direito à vida) sobre o segundo, por se tratar de "bem de maior valor," indisponível. Definitivamente não há que se falar em colisão entre direitos fundamentais. A colisão é aparente e não há, em sede deontológica, a possibilidade de priorizar normas com esteio em valoração. O drama da colisão pode ser dissipado por intermédio da teoria do direito como integridade (Direito como conjunto de princípios), de Ronald Dworkin. ${ }^{39}$ Feita esta constatação, advirtase que não existe colisão quando se trata de direitos fundamentais de um mesmo titular (cidadão). Com isso, retoma-se, aqui, a necessidade de o Judiciário, bem como a classe médica, revisitar posicionamentos. Afora o problema teórico acima afastado, o Judiciário não tem a competência de indicar qual é o tratamento médico mais indicado para um determinado paciente, nem a classe médica pode transfundir paciente "à força". Retomase, aqui, que a opção é de responsabilidade do paciente, genuíno titular do interesse "vida digna," da "liberdade de consciência" e "religiosa". Portanto, "(...) quando o processo de decisão é assim partilhado, o profissional de saúde age eticamente e demonstra respeito às crenças religiosas e demais valores de seu paciente". ${ }^{40}$ Dessa forma, não há que se falar em responsabilidade do médico por nenhum procedimento judicial (Ministério Público) ou éticoadministrativo (Conselho Regional de Medicina).

c) $\mathrm{Na}$ democracia não há nenhuma lei que obrigue alguém a se submeter à transfusão de sangue. Para tanto, viola a dignidade humana obrigar paciente a receber transfusão sanguínea contra a sua vontade. ${ }^{41}$

d) No Estado Constitucional e Democrático não existe razão para achar que o Judiciário é uma instituição pública que irá se responsabilizar por uma decisão eminentemente médica (que deveria ser optativa do paciente) no determinar uma transfusão de sangue, que, aliás, não é a única terapia que pode salvar vida. Aqui se faz necessário um comentário altamente relevante: o Judiciário, no Estado laico, tem que se posicionar de maneira neutra em tema religioso.

\footnotetext{
${ }^{39}$ DWORKIN, Ronald. O Império do Direito. São Paulo: Martins Fontes, 1999.

40 TJRS, $5^{a}$ Câm. Cív., AP 70020868162, Rel. Des. Umberto Sudbrack, J. 22.8.2007.

${ }^{41}$ TJRJ, $18^{a}$ Câm. Cív., Ag 13229/2004, Des. Marco Antonio Ibrahim, J. 5.10.2004.
} 
e) Não cabe aos hospitais, nem ao Judiciário, avaliar se uma determinada crença religiosa está correta ou não. Também não cabe aos juízes dizer se um método cirúrgico é mais acertado do que outro ou não. Nesse aspecto, todo cidadão é livre para pensar racionalmente a sua crença, trocá-la pelo esclarecimento científico ou, ainda, trocar uma discussão religiosa por uma jurídica, porque, na alta modernidade (sociedade multiética) o direito de um paciente escolher um determinado tratamento médico independe de religião. A bem dizer, seria o mesmo direito que pacientes possuem em realizar ou não uma quimioterapia, um transplante de órgãos ou uma determinada cirurgia.

f) Quanto ao médico que transfunde um paciente contra a vontade deste (e que não é informado a respeito da realização do procedimento), comete o profissional da saúde constrangimento ilegal previsto no CP, 146, além da possibilidade de responder civilmente pelos danos causados ao paciente, uma vez que "ninguém pode ser constrangido a submeter-se, com risco de vida, a tratamento médico ou a internação cirúrgica," nos termos do CC, art. 15. Como ficou visto, o Código de Ética Médica não é contra legem na parte ligada ao atendimento da vontade do paciente, e o fato de o profissional da saúde submetê-lo à transfusão e não informá-lo que o fez, à evidência, implica em responsabilidade civil e penal, bem como a abertura de um procedimento disciplinar administrativo, com punição do Conselho de Medicina, em virtude de não observar a vontade do paciente conforme determinação do Código de Ética Médica, deixando claro que as ressalvas contidas nos artigos 22 e 31, do referido CEM, podem ser questionadas, e são realmente questionadas por muitos juristas em âmbito de inconstitucionalidade, porque há no Texto de 1988 o reconhecimento de exercício de crença e liberdade de consciência (art. $5^{\circ}$, incisos VI e VIII), bem como do asseguramento da dignidade humana (art. $1^{\circ}$, inciso III) e da legalidade (art. $5^{\circ}$, inciso II). Igual raciocínio se estende também para o inciso I do $\S 3^{\circ}$ do artigo 146 do Código Penal.

g) Aqui, outros destaques em relação à técnica médica. Terapia sem sangue humano apresenta a mesma eficácia que o método tradicional, em todos os casos, sem restrição. E mais: não seria por preconceito, mas sim por conformismo, que alguns médicos relutam em utilizar técnicas alternativas. Alcançado este ponto, não se dispensa a reafirmação de outro: nas transfusões alternativas os riscos são os mesmos encontrados no tratamento sanguíneo ordinário (é necessário salientar, que mesmo na técnica tradicional, não há garantia de que o sangue resolva o problema).

h) Registra-se que, a depender do caso, a medida judicial a disposição do paciente que é avisado pela equipe médica que será adotado procedimentos médicos transfusionais é o mandado de segurança (via de regra), mas no deslinde da relação imediata não se afasta a ação ordinária com pedido de tutela antecipada. Afere-se ainda, que na análise concreta de cada caso, é possível falar até mesmo em habeas corpus, na hipótese de haver ameaça à liberdade de locomoção. 
i) Como visto, se o direito da Testemunha de Jeová é um direto líquido e certo, pois portador de liberdade de consciência e de crença, privacidade e dignidade humana (garantias asseguradas no Texto Constitucional brasileiro), evidentemente que a Testemunha ou qualquer outra pessoa (ateus, agnósticos, judeus, cristãos, islamitas, hindus, budistas, taoístas...) pode requerer método terapêutico que não a transfusão de sangue alogênico. O direito, neste caso, na lição de Rosemiro Leal, é portador de liquidez (autoexecutividade) e certeza (infungibilidade) pela decisão do legislador constituinte, e por isso "(...) reclama execução ininterrupta de mérito já pré-julgado (decidido) no horizonte instituinte do legislador originário da constitucionalidade vigorante. ${ }^{42}$ $\mathrm{E}$ assim se chega à conclusão final de que qualquer instauração procedimental em grau liminar antecipado (tutela antecipada - 273 do CPC), a fim de requerer autorização judicial para transfundir sangue em paciente, seria inócuo em face do que se expôs.

\section{BIBLIOGRAFIA}

ALEXY, Robert. Derecho y Razón Práctica. México: Distribuciones Fontamara, 1993. BULFINH, Thomas. O Livro de Ouro da Mitologia. Rio de Janeiro: Ediouro, 2002.

CARPIZO, Jorge. El poder: su naturaleza, su tipologia y los medios de comunicación masiva. Boletín Mexicano de Derecho Comparado (Nueva Serie), México, v. 32, n. 95, p. 321-356, mayo-ago. 1999.

CARVALHO NETTO, Menelick de. Requisitos pragmáticos da interpretação jurídica sob o paradigma do Estado Democrático de Direito. Revista de Direito Comparado. Belo Horizonte, v. 3, p. 482-486, maio 1999.

. A hermenêutica constitucional sob o paradigma do Estado Democrático de Direito. In. CATTONI, Marcelo (Coord.). Jurisdição e Hermenêutica Constitucional. Belo Horizonte: Mandamentos, 2004.

CORDEIRO LEAL, André. O Contraditório e a Fundamentação das Decisões no Direito Processual Democrático. Belo Horizonte: Mandamentos, 2002.

CRUZ, Álvaro Ricardo de Souza. Habermas e o Direito Brasileiro. Rio de Janeiro: Lumen Juris, 2006.

DWORKIN, Ronald. O Império do Direito. São Paulo: Martins Fontes, 1999.

HABERMAS, Jürgen. Direito e democracia: entre facticidade e validade. Tradução Flávio Beno Siebeneichler. Rio de Janeiro: Tempo Brasileiro, 1997.

HEIDEGGER, Martin. Que é uma Coisa? Lisboa: Edições 70, 1992.

LARAIA, Roque de Barros. Cultura: um conceito antropológico. Rio de Janeiro: Jorge Zahar, 2006.

LEAL, Rosemiro Pereira. Teoria Geral do Processo. Rio de Janeiro, Forense, 2010. . Relativização inconstitucional da coisa julgada. Belo Horizonte. Del Réu, 2005.

MADEIRA, Dhenis Cruz. Processo de conhecimento e cognição: uma inserção no Estado Democrático de Direito. Curitiba: Juruá, 2008.

\footnotetext{
${ }^{42}$ LEAL, Rosemiro Pereira. Relativização Inconstitucional da Coisa Julgada. Belo Horizonte. Del Rey, 2005, p. 27.
} 
MAUS, Ingeborg. Judiciário como superego da sociedade: o papel da atividade jurisprudencial na sociedade órfã. Revista Novos Estudos, São Paulo, v. 58, p. 183-202, nov. 2000.

MÜLLER, Friedrich. Métodos de Trabalho do Direito Constitucional. São Paulo: Max Limonad, 2000.

OLIVA, Alberto. Filosofia da Ciência. Rio de Janeiro: Jorge Zahar Editor, 2003.

OMMATI, José Emílio Medauar. O Princípio da Proporcionalidade e a Constituição como Ordem Concreta de Valores. Revista de Direito Constitucional e Internacional. São Paulo: Revista dos Tribunais. Ano 15, janeiro-março 2007, p. 109-128.

PEREIRA, André Gonçalo Dias. O Consentimento Informado na Relação MédicoPaciente - Estudo de Direito Civil. Coimbra: Coimbra Editora, 2004.

POPPER, Karl; ECCLES C. John. O Eu e seu Cérebro. Campinas: Papirus, 1995.

REPOLÊS, Maria Fernanda Salcedo. Habermas e a Desobediência Civil. Belo Horizonte: Mandamentos, 2003.

SILVA, Virgílio Afonso da. A constitucionalização do direito: os direitos fundamentais nas relações entre particulares. São Paulo: Malheiros, 2005. 